\title{
Study the Effect of Culture on Customer Loyalty on the Target Markets for Successful Export
}

\author{
Farzad Tarhani ${ }^{1} \&$ Solmaz Janfadaei ${ }^{2}$ \\ ${ }^{1}$ Malek-e-Ashtar University of Technology, Tehran, Iran \\ ${ }^{2}$ Islamic Azad University, Ghzvin, Iran \\ Correspondence: Farzad Tarhani, Malek-e-Ashtar University of Technology, Tehran, Iran. E-mail: \\ Tarhani123@Yahoo.com \\ Received: February 28, 2017 \\ Accepted: March 7, 2017 \\ Online Published: April 18, 2017 \\ doi:10.5539/res.v9n2p148 \\ URL: http://doi.org/10.5539/res.v9n2p148
}

\begin{abstract}
Export deals with a wide range of environmental factors, customers and competitors that are different with the domestic market. That's why market research and export promotion require management plans and appropriate procedures to their target markets and audiences. Exporter before entering a foreign market requires that by doing the necessary research on the marketrealizethe type of information required and how to collect it from a country other than their country and study about the cultural dimensions.

In fact, differences in the environment, cultural, legal, political, economic, financial, geographic, multinational markets, free trade zones and economic agreements include the level of economic development and the risks and major exporter that they should do an investigation to consider the conditions of satisfaction and thus increase customer loyalty.

This applied research was done aims to determine the effect of culture on customer loyalty at target markets for successful export using a descriptive method by a questionnaire that its validity and reliability was calculated. To analyze the issue of structural equations and correlation test was used. Based on the results, this study found a relationship between the cultural dimension, cultural beliefs and cultural values and traditions with customer loyalty at target market.
\end{abstract}

Keywords: export, target market, between nations culture, cultural beliefs, cultural values, customer loyalty

\section{Introduction}

The importance and role of exports in economic growth is no secret. High economic growth because the solution to many economic problems such as poverty, unemployment, inflation and unfavorable income distribution is considered, as an important policy goal to governments and the importance of this indicator is to the extent that it is now seen as a sign of power in the countries.

Achieving higher economic growth rate implies the adoption of appropriate economic policies that one of the main sectors of the policies is trade policies and exports (Dezhpasand \& Sabouri, 2008). Exports of goods and services play an important role in the country's economy. With the boom in trade with countries around the world are trying to make their policies more active.

Therefore, increased competition in trade that among these countries with a clear strategy and prospects of exporting our products have been more successful and have been able to attract loyal customers for their products (Arend \& Vasavada, 1995). How to create loyal customers in target markets in the exporting is complex and important issue that should be examined. One of these cases is the subject of cultural differences between the exporter and importer (Edwards, 1998).

Success in business is linked with cultural backgrounds and traditions of each nation. Basically, some nations can not attract and retain customers. On the contrary, in some cultures, politeness, modesty, humility and a lot of culture are institutionalized, which can lead to individual success and collective business.

When companies are expanding their markets in different countries of the world need to have strategies that doing most out of the product promotion costs for the different stages. Awareness of cultural differences in different countries could lead to more accurate planning. In the current international economic system of 
equations and economic relations are increasingly interacting with each other, the importance of active companies in the areas of international trade is increasing. Every day they are trying to increase their share in commercial markets and provide their goods and services with better quality and quantity.

In this competitive market, with products and quality service, customer retention is of particular importance. In fact, loyal customers are to vital (Tsai, 2011). Provide more services to them is convenient (Shugan, 2005), and are more willing to buy and pay (Seder et al., 2005). As well as positive word of mouth advertising are observed in them (Reichheld \& Sasser, 1990). After having loyal customers advertising costs and concerns of product promotion in organizations is reduced. Companies are constantly looking for marketing strategies to create loyal customers.

\section{Literature Review}

\subsection{The Concept of Culture}

Culture is a word that scholars of social science and anthropology researchers apply it and this term is wide spread and so useful that it also applied to other social sciences. Culture in terms of its expertise in the debate emerged in mid-nineteenth century in the writings of scholars and scientific use of the word culture in the late specified by Tyler (1917) as English anthropologist (Stanley, 1997, p. 62).

One of the basic principles of behavioral science begins with the discipline of anthropology and is one of sub-fields of anthropology, cultural anthropology, which is also closely associated with the study of organizational behavior. Cultural anthropology is influenced by acquired behavior of humans and their culture and dealing with culture is affected by this behavior. In fact, without a deep understanding of organizational behavior and cultural values of society can not be properly understood (Rahimnia, 2012, p. 47).

The role that culture plays in human behavior is one of the most important concepts in the behavioral sciences. Although this has not been fully evaluated. Culture is what people learn and determined how behave. How the culture exists, it must be said that culture is a phenomenon that comes with attention to natural and social forces.

Regional geography, history and events, common language and literature among the people, religion, economy and culture affect the way people's livelihood in and in combination with each other generate a set of values and beliefs that affect human behavior and makes communication between people easier (Hamidizadeh, 2012, p. 40).

In a very general concept, culture is the quality of life of a group of human beings who transmitted from one generation to another. According to Edgar Schein, culture can be understood as a phenomenon around us all the time. He believes that when a person brings a culture in organization could clearly how is emerged instead of getting to see its development and finally brought it under its influence, manage and change (Dehghani, 2013, p. 28).

In the other field, culture is applied by anthropologists and others who have examined the man. In this means the creation of ideas, habits, everyday objects are pointed out that emerged a complex compatibility between man and his natural environment (Haghighi, 2009, p. 49).

Culture has different meanings in Persian literature and most notably, education, knowledge, customs collection, science, education and arts.

\subsection{Value of Management}

Value of Management is a management model approach and value-oriented that emphasizes on stimulating people to develop skills and enhance synergies and innovation with the purpose of maximizing the overall performance of the organization. Value of management in the organizational level is based on a value-based corporate culture that this values include the interests of stakeholders and customer satisfaction (internal/external). Also in the operational level, use of appropriate tools and methods are concerned.

This standard introduced one of assumptions as dependency of value of management to senior management. Senior management tries to meet the expectations of stakeholders and customers to get the best output from the [inputs such as] assets, property, labor and material. Value management is obtained by Integration with operational managers and senior director in the organization. This issue is possible by focusing on outputs that are in line with overall business goals.

Organization social process: Another factor that is important in the creation and development of corporate culture is a social process. Through this process people open their place in the organization and how to attract in their organization, become familiar with norms and standards and learn appropriate behavior. 
Social processes in organizations is pre-service training and in-service training, or sometimes his people gradually recognize appropriate behaviors and norms are gradually accustomed to them. In the first case is formal and the second case is in the form of non-formal. Success of social process organization is related to the nature of the organization's culture and the prevailing norms in the organization (Rahimnia, 2012, p. 95).

\subsection{Traditions and Rituals}

Traditional are models formed in the organization as a sustainablehabit. Emphasis on the model, especially in a public ceremony behaviors, approach to work, people and clients, encouraged to follow the slogans and symbols associated meetings (every object, action, event, which is used to convey meaning), all expectations of the problem statement, individuals as well as their mutual expectations of the organization.

Myth: An example of the success of the organization's past history and outstanding work as model institutions or managers in the past recounts, with the aim of motivating employees to follow them from that pattern. Attachment created so that the employees and make them feel proud and to be proud member of the organization. Researcher other components of organizational culture change and continuity in terms of visibility and splits it into two levels.

So that, at a deeper level is less visible. Including the common values, even if they changed the band members will remain in the organization. In fact, the values that shape the behavior of the group. At this level it is very difficult to change culture. In this difference among military personnel in regard to financial matters, tapes or performance determined. At another level, which is visible, culture, behavior patterns shows that people new to learn automatically from the old staff. Culture can be changed at this level (Ibid, p. 96).

\subsection{Customer}

In market culture, customer is an individual that purchases goods or services that this ability and talent to select and operate simultaneously in one of the shopping is done. In this view, the individual customer's smart and wise about your needs well-studied and with valuation and taking his talent to select the features and deals (Rahimnia, 2012, p. 28).

. The customer is our reason for being employed.

. Client who pays our wages.

. The client is a person or entity that directly or indirectly goods and services to market (Mousavi, 2005, p. 55).

\subsection{Customer Types}

A) Customer outside a person outside the organization that receives our products or services (According to the site supplier).

B) Internal customer: internal customer is our partner companies involved in the commodity cycle (According to the site supplier).

\subsection{Customer Satisfaction}

Customer satisfaction is financing needs, expectations and demands of customers at the same time and in the same way that he wants (According to the customer site).

What is the effect of customer satisfaction on business?

Repeat satisfied customer purchase, on everyday goods.

Buy new products by the consumer for the lowest cost advertising.

Buy a new product or service requests by customers for goods or services provided by satisfied customers.

It is very important point that should not be forgotten that satisfied customers become unconscious in a medium free of charge for advertising, so from this channel will be added to the number of customers, organization or institution (According to the customer site).

\subsection{Identify Customer Expectations}

In previous models, business suppliers, regardless of customer demand, only goods and services with a focus on the production and supply facilities and their conditions. Ironically, many of whom were also successful, of course, this success of which is dependent on their performance in competitive conditions due to supply constraints and a lack of strong competitors were concerned. But, as noted in the new age, the presence of a strong competitor in the business scene, status changes and move towards customer satisfaction is in the agenda (Sanayei, 2007, p. 69). 
Customer satisfaction is the most important step in the process of identifying customer expectations. Identify customer expectations is not possible except by referring to him and get his views. The other era of suspicion and self-help customer has passed to the customer should be aware of the voices he heard. For this purpose and to identify customer expectations, nowadays suppliers, the use of statistical techniques to customer surveys, using different methods of postal, telephone and in-person act. In this regard, considering the factors that customer expectations of service, product or brand forms is of utmost importance. The most important of these factors are as follows (Zomorodian, 1994, p. 40).

\subsection{Loyalty}

By definition Richard Oliver and his colleagues, loyalty is continuous expression of a deep commitment to repurchase the product/desirable service $s$ in the future. By which to buy the same brand or set of brands duplicate the same according to the situational factors and effective marketing efforts leads to changing behavior (Davis-Sramek et al., 2007, p. 5; Russel- Bennet et al., 2007, p. 1254).

\subsection{Various Aspects of the Relationship between Satisfaction and Loyalty}

Studies on satisfaction and loyalty are divided into three categories. First category of service management has been adapted from literature and studies on the relationship between satisfaction and loyalty in general and in the company. According to their study background consent of loyalty that affect the profitability of the company. Second category focused on the individual level and Preservation customer based on the customer's intention to buy again.

These factors have a significant deficit due to the difference between intention and behavior. Second category argue that loyalty has been influenced by consent, even if their relationship is not logical. The third group are the few, the relationship between satisfaction and loyalty at the individual level have focused on the actual purchase data. Their findings suggest a weak relationship between satisfactions and buying behavior (Loyalty) (Bodet, 2008, p. 157).

Davis-sramek and others have suggested that the relationship between satisfaction and loyalty behavior is not linear and has two critical threshold level, when satisfied with the above specified thresholds (certain threshold) reach (the area of safety) purchasing behavior rapidly increases. When consent is reduced to the level of the lower threshold (hydrophobic region) buying behavior quickly reduced. Between the thresholds level (reflection area) is constant purchasing behavior. They believe that consent should be large enough to stimulate behavioral loyalty or low enough to reduce it.

\section{Research Method}

Scientific research based on the purpose of the research into three basic categories, application and evaluation are divided.

Fundamental research to develop and expand the kind of research that focused on theoretical knowledge and to expand human knowledge and the application of theoretical knowledge does not care. Theoretical knowledge gained from basic research to applied research to solve real-world problems are used.

Finally applied research and basic research impact assessment on solving real-world problems and their effects puts evaluated.

Since the results of this research to inform managers and employees is of particular audit firms, therefore, the aim of this research is applied research.

Since the data necessary to evaluate significance of comments made by members selected samples, obtained through a questionnaire survey, therefore based on the location of research is descriptive survey. The instrument used in this study was a questionnaire that its reliability Cronbach's alpha was $79 \%$, validity of the ranging method was performed. To analyze the questions and hypotheses descriptive and inferential statistical methods were used, including correlation and structural equations are. 


\subsection{Descriptive Analysis of Data}

\subsubsection{Status of Respondents in Terms of Gender}

Table 1. Table frequency and percentage of sample members based on gender

\begin{tabular}{ccc}
\hline Percent & Frequency & Gender \\
\hline 25.06 & 96 & Men \\
74.93 & 290 & Women \\
100.0 & 386 & Total \\
\hline
\end{tabular}

According to the data in the table can be argued that the highest frequency of $74.9 \%$ for men and the frequency is equivalent to 25.06 percent of the women depicted in the diagram.

\subsubsection{Status of Respondents in Terms of Education}

Table 2. Table frequency and percentage of sample members based on education

\begin{tabular}{cccc}
\hline Accumulative percent & Percent & Frequency & Education \\
\hline 7.90 & 7.90 & 31 & Associate degree \\
49.06 & 41.14 & 159 & BA \\
94.54 & 45.50 & 175 & MA \\
100.0 & 5.46 & 21 & Phd \\
& 100.0 & 386 & Total \\
\hline
\end{tabular}

\subsubsection{Status of Respondents by Age}

Table 3. Table descriptive statistics of the sample based on age

\begin{tabular}{ccccc}
\hline Maximum & Minimum & Standard deviance & Average & Variable \\
\hline 52 & 25 & 6.43 & 38.51 & Age \\
\hline
\end{tabular}

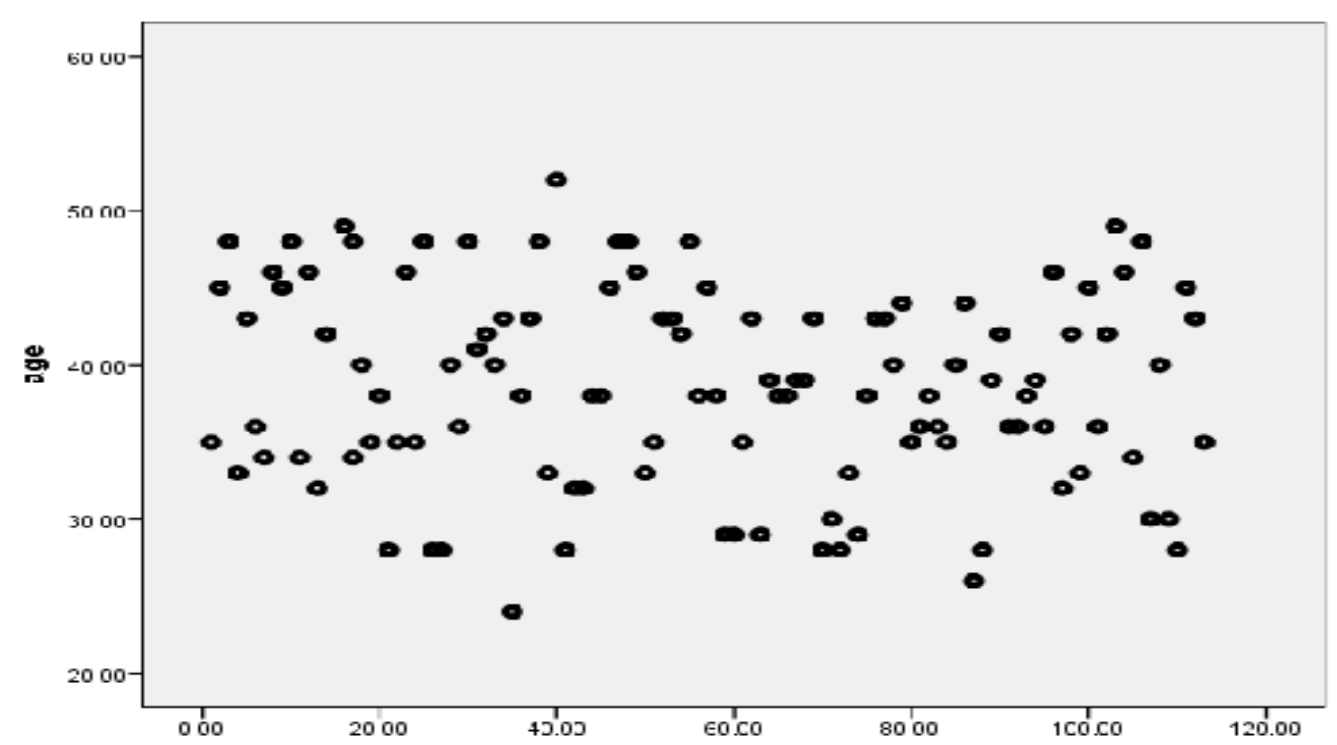

Figure 1. Status of respondents in terms of age 
The scatter plot above shows that the majority of respondents in the age category 35-45 years respectively.

\subsection{Check the Normality of Data}

Before testing the hypothesis normality of the data must be monitored to determine whether parametric test can be used or not?

To check the normality of the variables we use the Kolmogorov.

Table 4. Check the normality of research data

\begin{tabular}{ccc}
\hline Significant level & Kolomogrov-Smironv & Variable \\
\hline 0.878 & 0.590 & Loyalty \\
0.838 & 0.619 & Cultural beliefs \\
0.662 & 0.729 & Cultural values \\
0.733 & 0.687 & Cultural traditions \\
\hline
\end{tabular}

Given that the level of significance for all study variables is greater than 0.05 , non-parametric tests we used to test these variables.

\subsection{Research Model Using Structural Equation Lisrel}

The model was estimated using LISREL software is as follows:

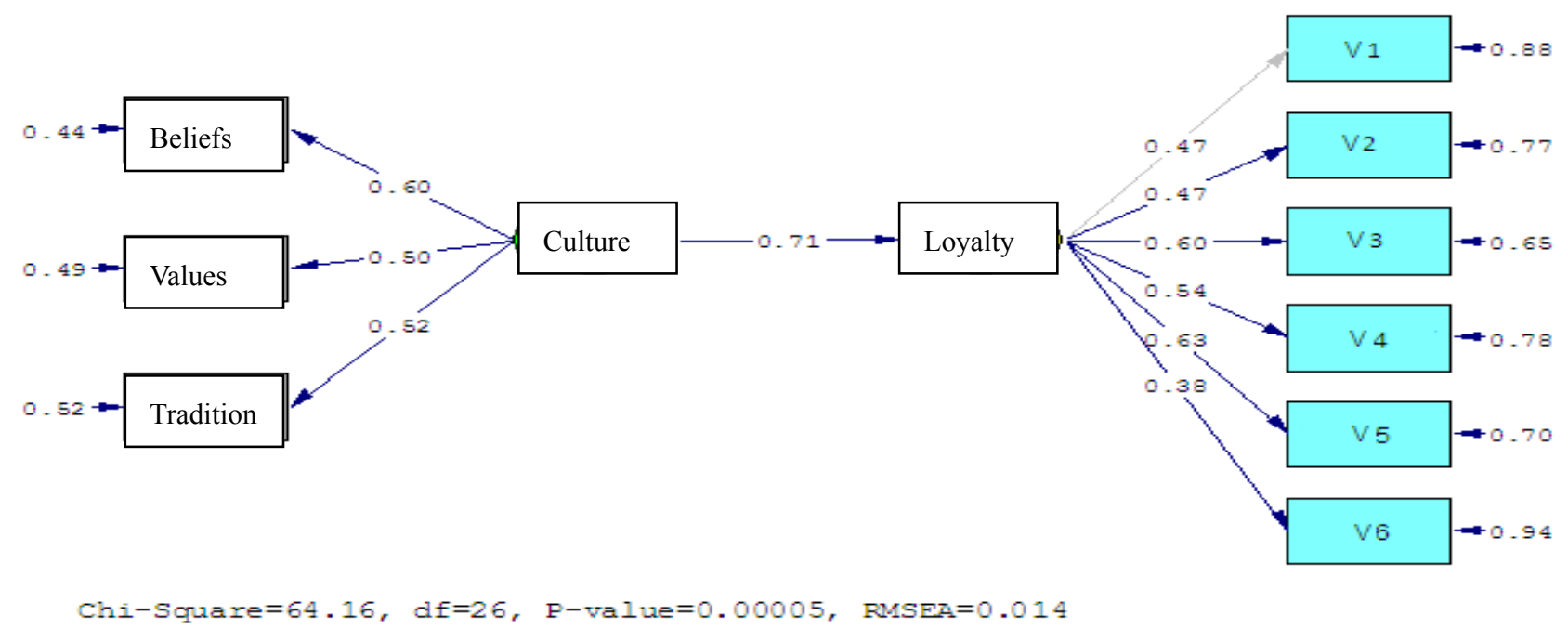

Figure 2. Original research model coefficients in standard mode

Structural equation modeling research in the diagram above shows the standard coefficients. All variables covert and overt turn this model into two categories. Observed variables (rectangles) or viewed directly by the investigator to be measured, while the latent variables (oval) or there is not to be measured directly, but based on inferred relationships or correlations between variables are measured. 


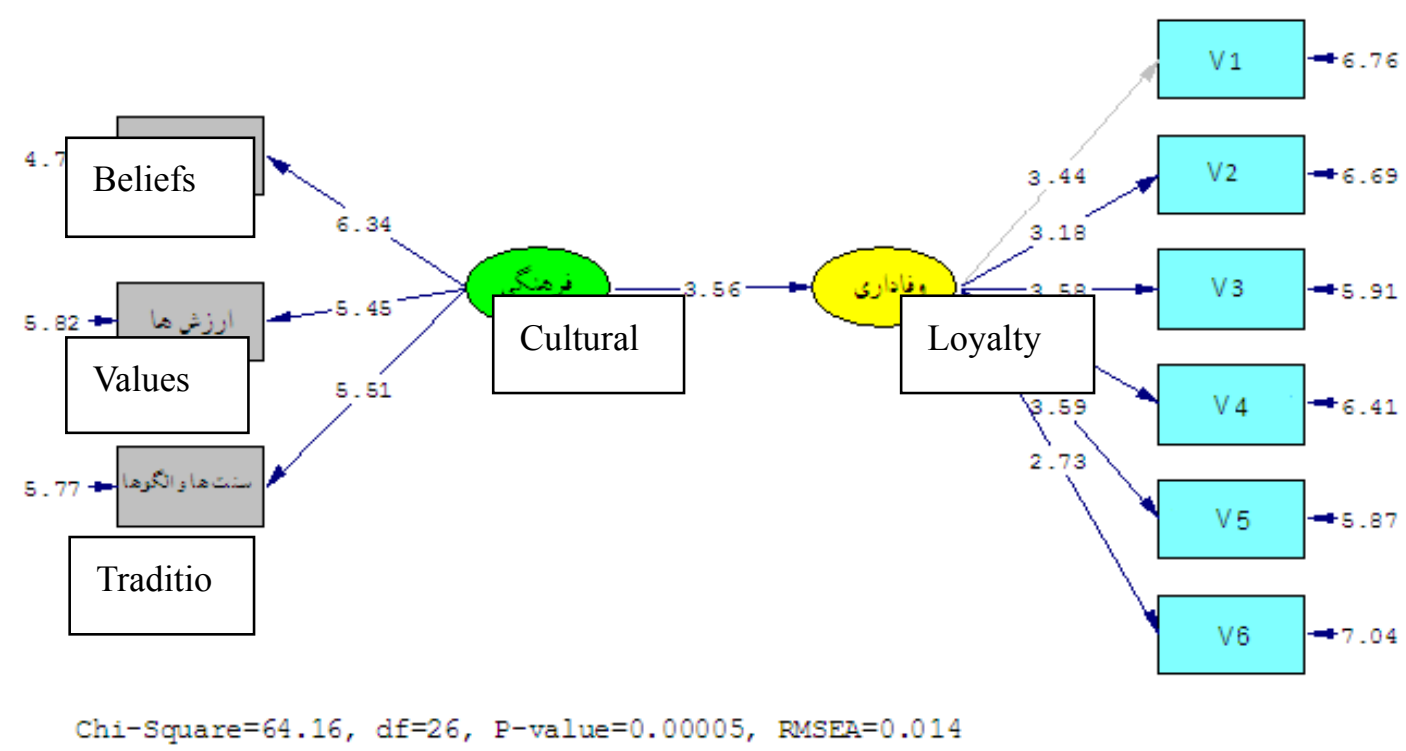

Figure 3. Structural equation modeling in significance mode (t-value)

Figure 3 Structural equation modeling study in a state of significant coefficients (t-value) shows. In fact, all the equations of the model (load factor) and structural equation using the statistic $t$ test. According to this model, the path coefficients and again in standard mode at $95 \%$ is significant. If the value is outside the range of -1.96 to +1.96 model in significance, shows that all factor loadings are significant in $95 \%$ confidence level. $\mathrm{T}$ calculated values for each factor loadings of each marker with its own structure or latent variable is above 1.96. Therefore, alignment can be validated questionnaire to measure concepts revealed at this stage.

\subsection{Interpreted of Model}

Table 5. Interpretation of structural equation modeling

\begin{tabular}{ccc}
\hline Allowed limit & Main estimate & Name of indicator \\
\hline Lower than 3 & 2.46 & Chi-square on freedom degree \\
More than 0.9 & 0.98 & Good fitted (GFI) \\
Lower than 0.09 & 0.014 & Root mean square error of estimate \\
More than 0.9 & 0.98 & Modified fitness \\
More than 0.9 & 0.93 & Normed fitness \\
More than 0.9 & 0.97 & Non-normed fitness \\
More than 0.9 & 0.98 & Increased fitness \\
\hline
\end{tabular}

In general, working with LISREL program, each of the indices obtained for model alone because there is no certainty fitness model. In some sources, the degree of freedom for the chi-square value is acceptable under 3 , is calculated 2.46 value in the model of this research. GFI measure represents a measure of the relative amount of variance and covariance is that the model is explained.

This criterion varies between zero and one that is increasingly closer to the number, the greater goodness of fit with the observed data. To check if a particular model compared with other models may, in terms of explaining the observed data set of how good acting softened fitness index (NFI), Not soft index fitness (NNFI), Increasing Fitness Index (IFI) and the Comparative Fit Index (CFI) is used.

The values top of 0.9 of this index suggests suitable fitting design model compared with other models is possible. Finally, to see how the model will combine fitness and savings, of the square root of the variance estimation 
error of approximation RMSEA powerful indicator is used. Stock RMSEA, the root mean square is approximate. In this study, the research model (0.014), respectively.

As the fitness characteristics in the Table above shows, the data of this study was to investigate the factor structure and theoretical foundation is a good fit and this shows in line with questions of theoretical structures.

\section{Research Findings}

- There is a significant relationship between cultural dimensions and loyalty.

Based on the cultural dimensions with loyalty that people have a coefficient of $0.71 \mathrm{t} 3.56$ is value. $\mathrm{T}$ value for this parameter (as a rule reject the null hypothesis error for values outside the range of five percent in the region of -1.96 to +1.96 . Each parameter model), greater than $96 / 1$ is obtained. Therefore, it can be concluded that hypothesis is accepted with $95 \%$ confidence, in other words, a statistically significant relationship between cultural dimensions and loyalty.

- There is a relationship between cultural beliefs and loyalty.

Based on the relationship between cultural beliefs with loyalty that people have a coefficient of $0.42 \mathrm{t} 4.95$ is value. $\mathrm{T}$ value for this parameter (as a rule reject the null hypothesis error for values outside the range of five percent in the region of -1.96 to +1.96 . Each parameter model), greater than $96 / 1$ is obtained. Therefore, it can be concluded that hypothesis is accepted with $95 \%$ confidence, in other words, a statistically significant relationship between cultural beliefs and loyalty is.

- There is a relationship between cultural values and loyalty.

Based on the relationship between cultural values and loyalty that people have a coefficient of $0.35 \mathrm{t} 4.50$ is value. $\mathrm{T}$ value for this parameter (as a rule reject the null hypothesis error for values outside the range of five percent in the region of -1.96 to +1.96 . Each parameter model), greater than 1.96 is obtained. Therefore, it can be concluded that hypothesis is accepted with $95 \%$ confidence, in other words, the relationship between cultural values and loyalty is statistically significant.

- There is a relationship between tradition and cultural traditions and loyalty.

Based on traditions and cultural practices that loyalty has a coefficient of $0.36 \mathrm{t} 4.53$ is value. T value for this parameter (as a rule reject the null hypothesis error for values outside the range of five percent in the region of -1.96 to +1.96 . Each parameter model), greater than 1.96 is obtained. Therefore, it can be concluded that hypothesis is accepted with $95 \%$ confidence, in other words, between tradition and cultural traditions and loyalty relationship is statistically significant.

\section{Conclusions and Recommendations}

Export and marketing concept defines a specific organizational culture, a set of shared beliefs and values that consider the importance of putting the customer in strategy and operations of bypasses. Marketing is the most important step in export. Knowledge of foreign markets and ways to influence it, knowing the power cores, understanding competitors in the target country is the most important part that requires research and strategic intelligence gathering.

Exports as a commercial phenomenon, a conceptual framework, a business process, an adjustment process of supply and demand, creating physical desirability, time and place, the focus and the Equality and distribution, product definition is a process of transfer of ownership. From the perspective of economists is a social process that export goods and services from the producer to the consumer as guides that causes balance between supply and demand and provides social goals.

As you can see above definition refers to aspects of distribution and sales promotion. Exports can be defined from the the customer's perspective. If it is considered that the export of the final result, the work of trade. This definition makes clear that the emphasis should be on what is, and it makes economic sense for a company in a profession or trade. As long as a company can continue to meet customer satisfaction.

Attention to the cultural dimension correctly in addition to sales distribution and promotion include design and optimal pricing and thus satisfy customer and market demand caused exports to provide resources and this issue will follow the next steps in checking and attract talent market. Export deals with a wide range of environmental factors, customers and competitors that the domestic market are different. That's why market research and export promotion require management plans and appropriate procedures to their target markets and audiences.

An exporter before entering the foreign market, requires that doing the necessary research on the market and realize type of information required and how to collect it from the a country other than their country and cultural, 
the differences in the environment, cultural differences, legal, political, economic, financial, geographic, multinational markets, free trade zones and economic agreements, the level of economic development and involve risks and major exporter to the information they need that they should do an investigation, to consider the conditions of satisfaction and thus increase customer loyalty.

According to a study and recommended that the importance of this issue;

- Pay attention to the values and beliefs of the community in the provision of goods.

- Policies adopted by customers in products can be observed.

- The mystical and immaterial aspects of products can be observed.

- Pay attention to the type of products in the consumer society.

- Use the value patterns with the appearance and packaging.

\section{References}

Ahmadi, H. (2009). Position and Ethnicity in Iran. Tehran: Ney Publishing.

Askarian, M. (2001). Sociology of Education. Tehran: Danesh Afrooz Publication.

Atafar, A. (1996). Corporate culture and how to change it. Work culture Seminar of Isfahan.

Azizi, S. et al. (2012). Examined the relationship between brand equity and customer consistent brand personality. A New Marketing Research Management, 4(2), 63-81.

Dehghani, S. M. et al. (2013). Structural equation modeling approach in explaining the effect of experience, trust and brand loyalty on brand equity. Journal of Marketing Management, 21, 102-117.

Dezhpasand, F., \& Hossein, S. (2008). The effect on the growth of non-oil exports of Iran's development policy. Economic Sciences, 1(3).

Edwards, S. (1998). Openness, Productivity and Growth: What Do We Really Know? The Economic Journal, 108(2), 383-398. https://doi.org/10.1111/1468-0297.00293

Haghighi, M. A. (2009). The role of culture in sustainable development; analysis of Iranian culture. Monthly Cultural Engineering, 4(38), 76-86.

Haghighi, M., Seyyed, M. M., \& Masoud, K. (2007). Faithful service: Service quality effects and the mediating role of customer satisfaction. Tehran University: Knowledge Management, 60.

Hamidizadeh, M. R. et al. (2012). Examine the relationship between personality dimensions and brand equity and moderating role of moral traits. New Journal of Marketing Research, 2(3), 35-50.

Irannejad, P. M. (2013). Principles of thesis writing. Tehran: Modiran Publication.

Lemon, K., Rust, R., \& Zeithaml, V. (2001). What drives customer equity Marketing Management.

Lings, L. N. (2000). International marketing and supply chain management. Journal of Service Marketing, 14(1), 27-43. https://doi.org/10.1108/08876040010309194

Mattila, A. S. (1999). The role of culture in the service evaluation process. Journal of Service Research, 1(3), 250-261. https://doi.org/10.1177/109467059913006

Rahimnia, F., \& Fatemi, S. Z. (2012). Examined the mediating role of customer-based brand equity impact of successful communication with customers and brand image in Mashhad 5 star hotels. A New Marketing Research Management, 1(2), 73-92.

Reichheld, F. (2003). The one Number You Need to Grow. Harvard Business Review.

Reykowski, J. (1994). Collectivism and individualism as dimensions of social change. Cross Cultrual Research and Methodology Series-Sage, 18(2), 276.

Ronald, I. (2004). Cultural change in advanced industrial society (V. Maryam Trans.). Tehran: Kavir Publications.

Rust, R., Lemon, K., \& Zeithaml, V. (2004). Return on marketing: Sing customer equity to focus marketing strategy. Journal of marketing, 68(1), 109-127. https://doi.org/10.1509/jmkg.68.1.109.24030

Sarmad, V., Bazargan, A., \& Hejazi, E. (2005). Research methods in behavioral sciences. Tehran: Agah Publications. 
Shugan, S. (2005). Brand loyalty programs: Are they shams? Marketing Science, 24(2), 185-193. https://doi.org/10.1287/mksc.1050.0124

Stanley, D. (1997). Culture management (M. Nasser, \& M. G. Parichehr Trans., 2nd ed.). Tehran, Morvarid.

Stephen, R. (1995). Organizational Behavior Management (Vol. 3, P. Ali. \& M. A. Seyed Trans., 1st printing). Tehran Institute for Trade Studies and Research.

Tabibi, S. J. et al. (2013). Developed a thesis, dissertation, research projects and scientific papers. Tehran: Firdous.

Tsai, S. P. (2011). Fostering international brand loyalty through committed and attached relationships. International Business Review, 20(5), 521-534. https://doi.org/10.1016/j.ibusrev.2010.10.001

Zomorodian, A. (1994). Change management, strategy and application of new patterns (1st ed.). Industrial Management Institute, Tehran.

\section{Copyrights}

Copyright for this article is retained by the author(s), with first publication rights granted to the journal.

This is an open-access article distributed under the terms and conditions of the Creative Commons Attribution license (http://creativecommons.org/licenses/by/4.0/). 